GP48 GERMAN NEWBORN SCREENING PROGRAMME
IDENTIFIES FIRST CASE OF MCADD IN AN IRISH
TRAVELLER CHILD IN THE ROI

${ }^{1}$ Husnain Mahomed*, ${ }^{1}$ Peter O'Reilly, ${ }^{1}$ Therese Martin, ${ }^{2} J o a n n e ~ H u g h e s, ~{ }^{1}$ Anne Marie Murphy. 'University Hospital Limerick, Limerick, Ireland; ${ }^{2}$ Children's University Hospital, Temple Street, Dublin, Ireland

\subsection{6/archdischild-2019-epa.114}

Aim/Purpose To report the first case of Medium-chain acylCoA dehydrogenase deficiency (MCADD) in an Irish Traveller child in the Republic of Ireland (ROI).

Methodology We describe the clinical presentation, outcome to date and genotype of a now 8 month old female infant from the Irish Traveller Community who was identified through newborn screening in Germany where she was born.

Results An 8 month old girl from the Irish Traveller Community returned to Ireland and was referred to local Paediatric services by her family doctor having been diagnosed with MCADD on the National Newborn Screening Programme in Germany.

Her mother had travelled to Germany for a wedding and developed placenta praevia. It was felt that it was too dangerous for her to travel back to Ireland at the time. The child was born at term by spontaneous vaginal delivery.She had a positive newborn screening test for MCADD. .Subsequent metabolic tests confirmed this diagnosis.

On assessment at 8 months of age she was found to be robust, thriving with normal neurodevelopment. There have been no incidents of infection or hypoglycaemia. She has not required hospitalisation. Vaccines are up to date with no adverse incidents.

She was found to have the common p.(Lys329Glu), c. $985 \mathrm{~A}>\mathrm{G}$ pathogenic mutation of the ACADM gene.

Conclusions This case highlights the success of the newborn screening programme in Germany and early medical intervention in MCADD. To our knowledge this is the first confirmed case of this recessive disorder in the highly consanginous Irish Traveller community in the ROI.

\section{GP49 MUNCHAUSEN BY PROXY SYNDROME IN THREE SIBLINGS DIAGNOSED AS ISOVALERIC ACIDEMIA}

Sibel Öz*, Sebile Kılavuz, Deniz Kor, Fatma Derya Bulut, Berna Şeker Yılmaz, Aysun Karabay Bayazıt, Halise Neslihan Önenli Mungan. Cukurova University, Adana, Turkey

\subsection{6/archdischild-2019-epa.115}

Introduction Isovaleric acidemia (IVA) is a rare autosomal recessively inherited metabolic disorder caused by deficiency of isovaleryl-Co A dehydrogenase. Clinical signs are refusal of feeding, vomiting, lethargy, convulsions, metabolic acidosis, hyperglycemia/hypoglicemia, and foot odor in neonatal period. Munchausen by proxy syndrome is a complex form of childhood abuse that can be sometimes severe and fatal. A caregiver intentionally creates some symptoms mimicking an organic disease or changing the laboratory samples that causes damages in child health.

Case The patient who was diagnosed as IVA at 2-months of age had no other metabolic attacks until the age of seven. After that, he was hospitalized in every 3-4 months with severe dehydration and renal failure and hemodiafiltration was performed. The levels of creatinin and potassium are incompatible with life and there were any sustaining clinical or electrocardiographical signs. His 2 year-old sister and 6 month-old brother who had also IVA were also hospitalized with recurrent encephalopathic status. As the family had a history of a child death without a known cause and the siblings had frequent hospitalizations in different medical centers and cities without a triggering factor, a more detailed anamnesis was obtained from the mother. Suprisingly this new history put forward the usage of antipsychotic/anatidepressive drugs in all siblings which lead to recurrent encephalopathies. However, renal insufficiency could not be explained until the mother's mixing of her urine to the blood samples of the child was observed in the clinic.

Conclusion Munchausen by proxy syndrome is a severe form of child abuse that can even result in death of the child if the diagnosis is not established in time. Although our patients had a known inherited metabolic disease with a defined mutation, the mother did not tell anything about this or sometimes told lies on the admissions to different medical centers. These confusing anamnesis easily lead the other physicians to the diagnosis of more common diseases like acute renal insufficiency, encephalities, and diabetes. Then, lots of unnecessary procedures was performed until the munchausen by proxy syndrome was thought. We present this case to emphasize thinking Munchausen by proxy syndrome with recurrent unexplained signs and symptoms even in the presence of a known disease in order to prevent undesirable results.

\section{GP50 AUTOIMMUNE ENCEPHALITIS WITH SEVERE CATATONIA AND THYROTOXICOSIS}

Maria Conejero*, Oliva Thomsen, Jonathan Bronstein. Universidad Católica de Chile santiago, Chile

\subsection{6/archdischild-2019-epa.116}

Previously healthy 12-year-old girl. Ten days before presentation to our center presented focal seizures with secondary generalization. Studied in a local hospital, was started on levetiracetam. 4 days before transfer to our center she became disoriented with visual and auditory hallucinations, orolingual dyskinesias, sleep disturbances, enuresis and gait instability with no fever or other associated symptoms. She was suspected to have autoimmune encephalitis, received 1 $\mathrm{gr} / \mathrm{kg}$ Immunoglobulins (IVIG), and transferred to our center.

At presentation, she was slightly tachycardic, inattentive, bradypsychic, with a decreased language fluency, disoriented in time and space, had orolingual dyskinesias, normal tone, and no nuchal rigidity or meningeal signs. No other relevant findings on physical exam.

Lumbar puncture showed leucocyte $20 \times u$ L, negative gram and culture, $\operatorname{IgG} 3,9 \mathrm{mg} / \mathrm{dL}$ (serum/LCR IgG index 0.43 ), IgG sintesis $-10.8 \mathrm{mg} / 24 \mathrm{hrs}$, albumin $16.4 \mathrm{mg} / \mathrm{dL}$ (serum/LCR albumin index 3.57 normal), positive NMDAR antibody on LCR and positive oligoclonal bands.

Persistently tachycardic, with a TSH of $0.206 \mathrm{uUI} / \mathrm{L}$, Free T4 $2.82 \mathrm{ng} / \mathrm{dL}$, T3 $91.9 \mathrm{ng} / \mathrm{dL}$, elevated Antiperoxidase antibody $(113.88 \mathrm{UI} / \mathrm{mL})$ and Anti Thyroglobulin $(57.42 \mathrm{UI} / \mathrm{mL})$ were compatible with thyrotoxicosis. Beta blockers were started with an adequate response. 